This item was submitted to Loughborough's Research Repository by the author.

Items in Figshare are protected by copyright, with all rights reserved, unless otherwise indicated.

\title{
Teaching inclusively: Are secondary physical education student teachers sufficiently prepared to teach in inclusive environments?
}

PLEASE CITE THE PUBLISHED VERSION

http://dx.doi.org/10.1080/17408989.2011.582487

\section{PUBLISHER}

(c) Association for Physical Education. Published by Taylor and Francis

\section{VERSION}

AM (Accepted Manuscript)

\section{PUBLISHER STATEMENT}

This work is made available according to the conditions of the Creative Commons Attribution-NonCommercialNoDerivatives 4.0 International (CC BY-NC-ND 4.0) licence. Full details of this licence are available at: https://creativecommons.org/licenses/by-nc-nd/4.0/

\section{LICENCE}

CC BY-NC-ND 4.0

\section{REPOSITORY RECORD}

Coates, Janine. 2019. "Teaching Inclusively: Are Secondary Physical Education Student Teachers Sufficiently Prepared to Teach in Inclusive Environments?". figshare. https://hdl. handle.net/2134/25019. 


\section{Teaching Inclusively: Are Secondary Physical Education Student Teachers}

\section{Sufficiently Prepared to Teach in Inclusive Environments?}

Janine Coates

Key words: Inclusion, Teacher Training, Special Educational Needs, Physical Education, Student Teachers

\section{Practitioner summary:}

In recent years, increasing numbers of children with special educational needs (SEN) have been accepted into mainstream schools, due to inclusion rising up the political agenda. Research, however, has shown that student and experienced PE teachers do not perceive their inclusion training as sufficient in preparing them to teach children with SEN. This study examines if student PE teachers are sufficiently prepared to teach in inclusive environments. A semi-structured questionnaire was administered to 107 student secondary PE teachers. Findings illustrated that student PE teachers did not perceive their initial teacher training (ITT) as effective in preparing them to teach inclusively. These findings provide scope for curriculum design changes on ITT courses at higher education, suggesting that inclusion should be embedded on ITT courses, providing students with more hands-on experience of teaching children with SEN. 


\section{ABSTRACT}

\section{Background}

Contemporary English educational guidelines, such as the National Curriculum (NC) have adopted inclusivity in the way children with special educational needs (SEN) are taught. Therefore, inclusion has risen up the political agenda, resulting in more children with SEN being taught in mainstream environments. Empirical research has attempted to examine PE teacher's perceptions of inclusion. However, it is evident that PE teachers perceive the training they receive during initial teacher training (ITT) as a constraint on their practice with specific regard to teaching children with SEN.

\section{Purpose}

This study aimed to determine if student secondary PE teachers are sufficiently prepared to teach children with SEN inclusively, by examining their training at ITT as well as their perceived preparedness and confidence to teach inclusively.

\section{Participants and setting}

107 students from a four-year BA (Hons) and a PGCE secondary PE ITT course attending a North West England ITT institution participated in the study.

\section{Research design}

Survey research was implemented to examine if student secondary PE teachers attending two different ITT courses were sufficiently prepared to teach in inclusive environments.

\section{Data collection}

A 31-item semi-structured questionnaire comprising predominantly of closed questioning, was used for this study. Open-ended questions were included to collect qualitative data, 
intended to add richness to the data and explore students' perceptions. Questions focused upon respondent's inclusion training at ITT, the perceived effectiveness of this training, students' preferences in teaching, experience of teaching children with SEN, as well as their perceived preparedness and confidence to teach inclusively.

\section{Data analysis}

Quantitative data was analysed statistically using SPSS. Qualitative responses were analysed using NVivo. Comparisons were made between the two different participant groups, in order to determine whether curriculum differences impacted on perceived preparedness and confidence to teach inclusively.

\section{Findings}

Findings showed that BA (Hons) student teachers received more formal inclusion training compared with the PGCE students. Yet, student teachers from both courses were being expected to teach children with a range of different SEN within their in-school placements. As such, students from both courses demonstrated a desire to receive more formal handson experience of teaching inclusive PE, with particular reference to activity specific SEN training. Finally, it was discovered that while the participants generally felt prepared and confident to teach children with SEN, displaying positive attitudes for inclusion; few attributed this to their training at ITT, deeming their inclusion training at ITT as ineffective.

\section{Conclusion}

PE ITT providers need to embed aspects of inclusion training throughout their curricula so that inclusion is not perceived as a bolt-on option. This will ensure student and newly qualified teachers (NQTs) have the experience and knowledge to teach inclusively. This training should include activity-specific SEN training, and student teachers should be provided with opportunities during their in-school placements to plan for and teach children with a range of different SEN. In doing this, it is expected that NQTs will enter teaching 
prepared, with the necessary skills to deliver inclusive PE lessons, thereby, confidently meeting the needs of their pupils.

\section{Introduction}

This paper sets out to examine the preparedness and confidence of student Physical Education (PE) teachers within one North West England Initial Teacher Training (ITT) institution, in order to determine if they are sufficiently prepared to teach in inclusive PE environments.

Since the publication of the Warnock Report (Warnock, 1978), there has been a push for inclusive education, culminating in current policy, such as the Special Educational Needs and Disability Act (SENDA) (DfES, 2001b). These policies emphasise the need for children with SEN to be educated in mainstream schools, alongside their peers, using a curriculum suitable to meet the needs of all pupils (DfES, 2004a). Inclusion refers to the modification of school programmes, curricula, and material resources to meet the needs of the child. It requires change at a policy and practical level (Booth et al, 2000). As such teachers need to adapt their teaching practices, and there is a call for political and educational bodies to revise legislation and implement strategies to meet the needs of the individual children. Therefore, inclusion requires radical restructuring of schools in order for them to embrace all children, regardless of their diverse needs (Vickerman, 2007).

Inclusive education emphasises change at a social policy and practice level, and therefore follows the social model of SEN (Jones, 2005). It takes responsibility away from the individual child for adapting their learning styles, and calls for education providers to encourage diverse learning and provide provision to promote the abilities of all children. Alternatives to inclusion are integration and segregation, whereby children with SEN are educated away from their peers. This supports medical models of SEN, which view difficulties as being located within the child, calling for the child adapt to fit in with existing 
provision, or to attend special, segregated schools. Inclusion, on the other hand, advocates social models, and promotes structural change in education provision, and as such, is the preferred context for educating children with SEN, advocated by the UK government (DfES, 2001a, DfES, 2005) and academics alike (e.g. Ainscow et al, 1999; Farrell, 2000; Norwich, 2002; Low, 2007, etc).

It is worth noting here, however, that inclusion is not a concept limited to an English context. It is internationally favoured, with a number of countries embracing the inclusion philosophy in order to meet the needs and rights of all children to be educated (Hodkinson and Vickerman, 2009). Worldwide agencies, such as the United Nations (UN) have developed specific international legislation to ensure all children, including those with SEN and disabilities have equal access to education (UN, 2006). Several of these countries share similar policies to the English system (Hodkinson and Vickerman, 2009). As such, it is apparent that the inclusion of children with SEN in mainstream education is not only an issue situated within the English system, it is a philosophy which is globally sought after.

Inclusion requires the adaptation and modification of resources and delivery of lessons to effectively ensure all children are able to participate actively and access education. The English government, in recent years, has ensured inclusion has been at the forefront of the educational political agenda and this is evident through the plethora of policy and government documentation available to support inclusion and provide guidance to teachers and schools in ensuring they are able to meet the needs of all learners (for example, see DfES, 2001a; DfES, 2001b; DfES, 2004; DfES, 2005). Moreover, currently $57.2 \%$ of all children with SEN attend mainstream schools (DfES, 2007), and this number is set to increase with political agenda pushing for inclusive education (DfES, 2004; Vickerman, 2007; Vickerman and Coates, 2009). 
PE has recently increased in public and political awareness due to increases in childhood obesity and related diseases, and decreased activity levels in the nation's youth (Coates and Vickerman, 2008). The Government has responded to this by issuing guidelines such as the National Curriculum (NC) Inclusion Statement applicable to the PE curriculum (Qualifications and Curriculum Authority (QCA), 2009) and the Physical Education and School Sport for Young People strategy (PESSYP) (Department for Children, Schools and Families (DCSF), 2008). These not only promote increased physical activity for all children through PE and extra-curricular sporting opportunities, but provide guidelines about how to adapt teaching styles to ensure the inclusive delivery of PE lessons so that all children's needs are met. However, the implementation of such strategies - whether specific to PE, or education in general, requires teachers to not only understand the values associated with inclusive education, but to have an awareness about how to adapt their teaching styles to effectively respond to the diverse needs of their pupils, and therefore support inclusive education (Clark et al, 1999; Vickerman, 2002; Morley et al, 2005; Smith and Thomas, 2006; Vickerman and Coates, 2009).

In light of this, this paper gives an analysis of research data which attempts to understand the extent to which secondary PE student teachers feel prepared and confident, in terms of the training they receive through ITT, to teach children with SEN in inclusive PE lessons. In doing so, it will provide scope for evaluating the implementation of ITT higher education programmes within PE with regard to ensuring future PE teachers are fully prepared to teach children with a range of diverse needs; and that they have the confidence and knowledge to do this effectively with the child's needs in mind.

In order to achieve this, attention must first be given to understanding the current training requirements for student secondary PE teachers in achieving Qualified Teacher Status (QTS), a formal requirement for all practicing teachers. In addition the perceptions of both student and experienced PE teachers about their experiences of inclusive training and 
teaching children with SEN from previous literature and research will be appraised. This will contextualise the current research within national teacher training frameworks, whilst also presenting current knowledge regarding the perceptions of teachers about inclusive education in PE settings.

\section{PE Initial Teacher Training}

The training of secondary PE student teachers in England, leading to QTS is regulated by the Training and Development Agency for Schools (TDA), in collaboration with the DCSF. All teachers who are employed in state maintained schools must achieve QTS in order to teach and, as such, standards for achieving QTS have been devised and are used in the assessment of professional practice (TDA, 2006). Whilst student teachers who complete ITT do not automatically receive QTS, ITT provides student teachers with the professional skills and knowledge necessary, as a newly qualified teacher (NQT), to meet the standards set out to achieve QTS. In terms of inclusive teaching, it is currently necessary for student teachers to display an ability to prepare for and differentiate methods, or seek guidance about children with SEN in order to receive QTS (ibid S3.3.4, TDA, 2006). In completing this, student teachers must demonstrate the ways in which they plan and modify programmes to meet the needs of their pupils, both with and without SEN; however, research indicates that this standard is often only achieved through ad-hoc and informal in-school practice (Golder et al, 2005). Moreover, Golder et al (2005) argue that student and newly qualified teachers experience with, and familiarity of, children who have a range of different SEN is often limited. Furthermore, there is no formal assessment strategy in determining whether a student teacher is able to meet children's specific needs as this mandatory requirement can be met by simply discussing with a more experienced member of staff the ways in which the child's needs might be met (Golder et al, 2005; Vickerman and Coates, 2009). Similarly, Vickerman and Coates (2009) indicate that assessment on inclusive practice is irregular, with only $27 \%$ of their trainee teacher respondents stating they had any specific SEN assessment as part of their training. Yet, Morley et al (2005) argue that assessment of the knowledge, understanding and application of inclusivity is necessary for PE ITT providers to 
make valid judgements about the ability of trainee teachers, and their awareness and attitudes towards SEN.

Legislative arguments suggest that it is highly important that teachers have the confidence and understanding to deliver inclusive education (DfES, 2001a; 2004), given the increasing numbers of children with SEN forecast to be in attendance at mainstream schools (DfES, 2004). However, it is not possible to achieve inclusive education if the standards which are in place to ensure it are ambiguous, overly simplistic and vague. In light of this, Robertson (1999:171) argues that the current standards for QTS, "are too simple, slight, procedural and compliant in design to be of great value, and they are unlikely to further the long-term development of inclusive education". He goes further to express the fear that training and recently qualified teachers are required to be compliant too much with standards, which, he claims, may lead to neglect in the understanding and developing skills necessary for inclusive education.

It is necessary, not only for the standards surrounding inclusive teaching to be made more clear for student teachers, but that ITT curricula promote inclusive awareness to students teachers. Morley et al (2005) and Vickerman and Coates (2009) indicate that assessment of inclusive skills and practice should be a requirement within ITT programmes in order to ensure that future teachers are able to demonstrate their ability and preparedness to teach children with SEN inclusively. However, according to the Quality Assurance Agency (QAA) for Higher Education (HE) (QAA, 2007), there is no set benchmark with regard to SEN and inclusion being a standard subject which must be addressed within education subjects at HE. Rather it is deemed an optional specialism, similar to subject specialisms like PE. Therefore, in relation to the current study which examines whether secondary PE student teachers are sufficiently prepared to teach in inclusive environments, attention will be given to understanding the ITT programme specifications for their chosen routes, in relation to how 
they address SEN and inclusion, as it is evident that this is not a mandatory topic taught within ITT (Vickerman and Coates, 2009).

\section{The Perceptions of Student and Experienced PE Teachers about Inclusion Training}

Existing literature demonstrates that student and NQT's do not feel confident or prepared to teach children with SEN in inclusive settings (Smith and Green, 2004, Morley et al, 2005, Vickerman, 2007, Coates and Vickerman, 2008; Vickerman and Coates, 2009). Moreover, it is apparent from the perceptions of PE teachers, in relation to teaching children with SEN, that this can be attributed to two key themes - unrealistic targets and a lack of SEN training

Unrealistic Targets - Research indicates that while student teachers and NQT's support the inclusion philosophy, there is a general feeling that achieving full inclusion in schools is an unrealistic target (Smith and Thomas, 2006). Moreover, Morley et al (2005) found that teachers felt that they could not adequately provide for children with SEN. It was reported that the teachers did not 'know' how to provide the best support to children with SEN, despite wanting to be able to help them. Teachers judged their ability to support the child based on the child's ability to participate, and therefore integrate into the lessons. Similarly, Smith and Green (2004) report that PE teachers do not believe children with SEN will be able to achieve the targets of the NC. They claim that although the NC now aims to include all children, its emphasis on 'achievement', 'skills' and 'performance' serve to exclude children with more profound difficulties. These perceptions, when examined broadly, indicate that the success of any inclusion strategy will be somewhat limited by the teachers scepticism about its success. If teachers are unwilling to accept and adopt inclusion ideologies positively in their practice, it will not be possible to achieve inclusion (Smith and Thomas, 2006; Coates and Vickerman, 2008). In addressing this, Avramidis et al (2000) argue that positive perceptions and increased confidence in inclusive teaching can be achieved through suitable and effective training through both ITT and continued professional 
development (CPD), and they demonstrate that teacher's who take responsibility for their training and teaching in terms of inclusivity tend to have more positive attitudes towards inclusion. As such, it is necessary to understand the ways in which student teachers perceive not only inclusion, but the ways in which their training prepares them to teach in inclusive environments in order to determine methods for improving their attitudes towards the education of children with SEN.

Lack of SEN training - Both teachers (Morley et al, 2005; Smith and Green, 2006) and ITT providers (Vickerman, 2007) indicate that there is a widespread lack of training relating directly to inclusive education both at ITT and through CPD. Morley et al (2005) found that some teachers had received no training on teaching children with SEN, while a few had opportunities to attend limited and ad-hoc training sessions. Similarly, Smith and Green (2006) indicate that the limited SEN training received at ITT and through CPD was construed to be one of the most constraining influences upon teaching practice. Moreover, only limited importance is placed on SEN in ITT (Vickerman, 2007); which further highlights a considerable lack of available training to student teachers. This evident dearth of training, according to Morley et al (2005: 100) has "serious repercussions for the quality of support experienced by children with SEN". This leads to a lack of confidence on the part of the teacher (Smith and Green, 2006), which in turn adds further disadvantage to the experiences of the child. Although government strategy claims to be improving the quality of training available to teachers both at ITT level and through CPD (DfES, 2004), it is clear that this training is, firstly not meeting the contextual requirements of teachers, in particular PE teachers; and secondly is not accessible enough to teachers to ensure and encourage further SEN training. Therefore, this study's primary aim is to examine the training that student PE teachers receive in relation to teaching in inclusive environments, and secondly how well this training prepares them to teach children with SEN confidently. This will help to determine whether PE ITT programmes are effectively ensuring future teachers are able to 
meet the standards for QTS and address possible areas for improvement within the ITT curriculum to more effectively prepare student teachers to work within inclusive PE settings.

\section{Methodology}

The purpose of this study was to examine whether student secondary PE teachers felt they were sufficiently prepared to teach in inclusive environments. In order to examine this, the decision was taken to explore the perceptions of students from one HE institution in the North West of England. The use of a single institution indicates a case study approach (Cohen et al, 2007) and this is advantageous in understanding the ways in which training is implemented and perceived by the student teachers of that particular institution, with curriculum development and change directed towards that particular institution. In normal circumstances, case study approaches make use of qualitative methodologies, gaining rich and detailed insight into the specific contexts being examined (Robson, 2006; Cohen et al, 2007). This study utilises predominantly quantitative methodology as a means of data collection. Nevertheless, the use of a single institution, with a solitary defined group of participants (trainee secondary PE teachers) categorises this study as a case study (Cohen et al, 2007), which may limit it's generalisability to other similarly defined groups. However, it gives light to the learning and teaching of this group at an institutional level, which is deemed necessary for improvements in teaching and learning to occur at a specific institution. Moreover, it highlights the use of scholarly research in implementing curriculum design changes within HE institutions.

Students from the two secondary PE ITT courses were invited to take part in the study. The courses were a four-year BA (Hons) PE, Sport and Dance leading to QTS programme, from which only final year students were invited to participate; and a one year Postgraduate Certificate in Education (PGCE) PE programme, from which all students were invited to 
participate. Only final year BA (Hons) students were invited to participate in order to assess the effectiveness of inclusive training within the full training programme. This allowed for some standardisation between the two sample groups, given their comparable immediacy to qualification as secondary PE teachers.

The HE institution was selected opportunistically due to personal links with the institution. In examining the institution programme specifications for PE ITT in both the four year BA (Hons) course and the PGCE PE course, it was noted that only the BA (Hons) course had any inclusion training listed as part of their curriculum, according to their programme specification. This presented an additional facet to the research, allowing for comparisons to be made between the two programmes, one of which had no formal requirement, or guidelines for inclusion modules within the course curriculum.

In total one hundred and seven student PE teachers participated in the study, of which $45.8 \%$ were on the four year BA (Hons) course and $54 \%(n=58)$ were on the PGCE PE course. The overall gender split was 43\% ( $n=47)$ male participants and $56 \%(n=60)$ female participants. The majority of the participants were between the ages of 18 and 25 (93\%, $n=100)$, and most were from a white British ethnic background $(96 \%, n=103)$. It is important to understand the demographics of the particular sample as this demonstrates not only the similarities in age but also of ethnic and cultural background. This is vital for gaining insight into the perceptions of this specific population, in relation to their ITT (Vickerman and Coates, 2009).

University ethical consent was granted for the research and adhered to the British Educational Research Association (BERA) ethical guidelines (BERA, 2004). Participants were required to give informed consent in order to participate, and were informed of their right to withdraw their participation at any point during the research process. 


\section{Data Collection and Analysis}

A 31 item semi-structured questionnaire containing both open and closed questions was developed and distributed to students (See appendix B for questionnaire). The use of a questionnaire not only allowed for a large sample to be generated (Bryman, 2001), but by including both open and closed questions, participants are able to provide a range of data, providing generalisable data through statistical analysis, but also rich insight into opinions and perceptions, through the collection of qualitative data via open questioning (Cohen et al, 2007). In addition to this, questionnaires have the advantage of increasing both reliability and validity within research, and as such, the study can be considered credible and transferable (Robson, 2006, Cohen et al, 2007). The questionnaire was split into four main sections, designed to assess students' preparedness and confidence in teaching students with SEN. These sections were 'About You', which collected demographic data; 'Training' which assessed the amount and types of inclusion training received as well as it's perceived effectiveness in preparing students to teach children with SEN, and improving their perceived confidence in doing so. The next section addressed 'PE Teaching', which assessed students' experience of teaching children with SEN and their personal preferences in teaching PE. Finally, 'Inclusion in PE' examined student teachers' attitudes toward inclusive teaching. The questionnaire items were developed through close examination with the literature (e.g. Avramidis et al, 2000; Morley et al, 2005; Vickerman, 2007; Vickerman and Coates, 2009), and each section was considered to be pertinent to evaluating and understanding the effectiveness of secondary PE ITT programs in preparing trainee teachers for inclusivity. Open questions on the questionnaire allowed students the opportunity to expand on their responses, and offer their opinions relating to the course they were enrolled on, and this was felt to be pertinent in developing a rounded perception from the student teachers. 
The questionnaire was administered face-to-face with student secondary PE teachers at the HE institution during a lecture agreed with by the relevant course leader. This was done to increase return rates, and as such, a return rate of $100 \%$ was achieved for both of the degree courses examined.

The quantitative data were analysed using a statistical analysis software programme (Statistical Package for the Social Sciences (SPSS) v17). Data was collated and examined statistically, in order to examine teacher training, perceived preparedness and confidence, as well as attitudes to inclusive teaching (please see Appendix B for SPSS output tables). Comparisons were made between findings related to the four year BA (Hons) student perceptions and those of the PGCE students using cross-tabulations, incorporating descriptive statistics (Bryman, 2001) in order to give an overview of the perceptions of student teachers. In addition, this allowed for analysis of how, for example, the length of time in training impacts upon preparedness, confidence and attitudes towards inclusive teaching. Only a very limited amount of qualitative data was collected through the open-ended questions on the questionnaire and this data was analysed thematically using a qualitative data analysis software package (NVivo v2). The findings were disseminated under the section headings given within the questionnaire (Training, PE Teaching, and Inclusion and $P E)$. These findings will now be demonstrated and discussed in relation to the research question "Are secondary PE student teachers sufficiently prepared to teach in inclusive environments?", and recommendations and conclusions will be given.

\section{Results}

Table one show the statistical findings generated from the data collected from the questionnaire. Data is shown in percentages to the first decimal place.

Insert Table One 
These findings will be discussed in detail within the following discussion sections.

\section{Findings and Discussion -Training}

The findings indicated that fewer one-year PGCE student teachers (78\%) believed that they had received inclusion training in comparison to the four-year BA (Hons) student teachers (98\%). In addition to this, the PGCE students (21\%) also received less PE specific inclusion training in comparison with the BA (Hons) students (35\%). Fifty-two per cent (52\%) of PGCE students compared with $75 \%$ of BA (Hons) students stated that they had received mandatory SEN training as part of their ITT. Similar results were demonstrated when examining in-school inclusion training, with $63 \%$ of BA (Hons) students receiving this, and only $52 \%$ of PGCE students receiving in-school inclusion training. It was clear that the fouryear BA (Hons) students benefitted from more comprehensive inclusion training as part of their course, both through mandatory SEN modules and in-school training. This could be attributed to the length of the courses being studied, with the PGCE students having less time within their over-prescribed curriculum to undertake inclusion training (Vickerman and Coates, 2009). Moreover, the PGCE students felt more time was needed for inclusion, with several indicating practical modules were needed, with some students stating that they require "university practical module on part of full module"; "still need to apply it to schools"; and that there were "not many lectures on specific inclusion strategies, could have done more practical sessions". This is supported by Vickerman and Coates (2009), who found that a majority of one-year postgraduate teacher trainees (up to $76 \%$ ) only spent between 0 and 5 hours on inclusion training over the course of their studies. However, these findings can also be explained by the formal requirement within the programme specification for the four year BA (Hons) for inclusion-specific modules to be undertaken.

Despite the difference in the amount of time spent on inclusion training for the two courses studies, similarities were found when examining the effectiveness of the training and its impact on perceived competence and confidence. Findings indicated that the majority of 
students on both courses (63\% for BA (Hons), and $66 \%$ for PGCE students) perceived the inclusion training they received as ineffective, feeling that more hands-on and activity specific training would be necessary. The majority also believed that this training should be delivered through mandatory taught modules and formal in-school training. When examining qualitative responses to these questions, many participants indicated that while the sessions they attended were informative and useful, they tended to only give a "basic overview" of SEN and inclusion, and as such many felt more training was needed. Moreover, some participants indicated that they received more effective training via their previous employment, rather than on their ITT courses. Similar findings have been demonstrated in previous research. Morley et al (2005); Lambe and Bones (2006) and Vickerman and Coates (2009) indicate that PE teachers feel that they require more training in order to teach inclusively and that hands-on experience of teaching children with SEN would be beneficial in increasing confidence and improving skills. In agreement with this, the training which was received by participants in this study was considered to increase both confidence (69\%) and competence $(69 \%)$ when teaching children with SEN, and as such, in improving the effectiveness of inclusive training at ITT, it is potentially possible to increase the confidence and perceived competence of student teachers even further.

It could be argued that rather than having bolt-on inclusion training, that inclusion should be embedded into the ITT curriculum, ensuring broad and balanced training for teachers (DePauw and Doll-Tepper, 2000; Hodge et al, 2004; Vickerman and Coates, 2009). Applying this argument, it is recommended that HE teacher trainers apply notions of inclusivity to all areas of the teacher training curriculum. According to DePauw and Doll-Tepper (2000) and Avramidis et al (2000), attitude change is a key factor in improving inclusive education, in that teachers need to have positive perceptions about inclusion and their teaching in order to promote successful inclusion in schools. By embedding the inclusion philosophy within the ITT curriculum, it might be possible to develop inclusive PE teachers, who are both confident in their teaching of children with SEN, and also competent in their abilities to do so. 
However, there is still the necessity, at present to provide modules specific to inclusive education, as it was felt by some students that these modules provided the theoretical knowledge they required for teaching inclusively. For example, one student stated that their mandatory module gave "different ideas and activities you can do. Also provides you with what you might do with certain types of pupils", and was therefore perceived as useful. Another student advocated mixed methods, stating "you need a mixture of theory of practice to deal with SEN. One alone cannot prepare you with a range of strategies that help to deal $\begin{array}{llll}\text { with } & \text { whildren } & \text { have }\end{array}$ A mixed approach to teaching inclusion is evidently useful to students and should therefore be adopted, acknowledging the varying learning styles of students and the advantages of both curricula designs.

\section{PE Teaching}

Previous research has indicated that the type of SEN children have in a PE lesson can impact on the ways in which PE teachers perceive their lesson outcomes (Hodge et al, 2004; Smith, 2004; Morley et al, 2005). In particular, these studies indicate that the type of SEN children have can be constraining on their practice. An examination of the findings of this study showed that all BA (Hons) student teachers had taught a child with SEN during their in-school placements, and that $93 \%$ of PGCE student teachers had. It was also evident that the four-year BA (Hons) students had taught a wider range of children with different SEN when compared with the PGCE student teachers, however the most prevalent type of SEN appeared to be behavioural, emotional and social development needs (BESD), with $84 \%$ of the overall sample having taught this group of pupils. While Morley et al (2005) indicate that children with BESD can be the most challenging to include in PE lessons, it is clear that student teachers require training relating to SEN and inclusion of a broad spectrum given that the vast majority are being expected to teach children with SEN, in line with government trends (DfES, 2004, 2007). Moreover, while the majority of PGCE students did not have as much experience of teaching a wide range of student with SEN, it was evident that children 
with a variety of different SEN were present in many students' lessons, and as such broad knowledge of these SEN and how to include all children would be necessary.

When examining teaching preferences and confidence in specific activity areas, findings showed that the majority of both BA (Hons) and PGCE students preferred to teach games activities (93\%), and similarly, they felt more prepared to teach children with SEN from this activity area (83\%), although BA (Hons) student teachers also felt prepared to teach inclusive gymnastics activities (71\%). The preference and preparedness for teaching games activities can be interpreted as evidence of the sporting tradition followed by PE teachers (Smith and Green, 2004). Smith and Green argue that PE teachers often place focus upon competitive games activities during PE lessons, and therefore more individual activities, such as dance and gymnastics - argued by some to be more conducive to inclusion (Penney, 2002; Smith, 2004), tend to be overlooked. Moreover, given the demographics of the student population examined in the study, it could be argued that these activities demonstrate a cultural preference for the age group and ethnic background of the students, given that the majority were between 20 and 30 years old, and of white British descent. It is possible, therefore that this finding is demonstrative of the students PE experiences and preferences.

Despite this, it is necessary for training PE teachers to have a broad understanding of inclusive teaching in all activity areas and as such, activity specific inclusion training would be beneficial. An example of this could be to demonstrate through practical sessions, how to differentiate for different children's needs, such as the use of a bell ball in football games for children with visual impairments). This was also indicated by the participants of this study who felt they required this type of training. Moreover, student teachers should be given the opportunity to apply their training to real-life PE settings (Morley et al, 2005; Vickerman and Coates, 2009), and as such opportunity should be made during in-school placements to teach inclusive lessons from a wide range of activities. This could go some way to increasing 
student teachers preparedness and confidence in teaching a wide range of activities inclusively.

\section{Inclusion and PE}

When addressing student teachers perception about inclusion in PE, it was found that overall the participants had positive perceptions about inclusion. Eighty-three per cent (83\%) of all participants agreed or strongly agreed that children with SEN should be included in mainstream schools. Similarly, $93 \%$ believed they understood what SEN was and $90 \%$ believed they understood what was meant by inclusion. Moreover, only $21 \%$ of all participants felt worried about teaching children with SEN. Despite this, when examining the difference between the two courses, it appeared that more BA (Hons) students felt worried about teaching children with SEN (25\% compared with $14 \%$ for the PGCE students). This can be contributed to the perception that perhaps not enough time is spent within ITT on inclusion. Some of the BA (Hons) students indicated in their qualitative responses, that the inclusion content was not substantial enough. One student stated "I don't feel I have vast knowledge or confidence to progress all SEN pupils", while another indicated that more hands on experience would have been more beneficial, saying it "would have been more applicable if joined to school experience". This finding is interesting, given that BA(Hons) students spend more time over the 4-year course on inclusive education, however, may raise questions about the quality of the content they are taught. It further demonstrates that more time is needed for inclusion training for student teachers in order to ensure they are confident and competent in their inclusive teaching.

Nevertheless $75 \%$ of students agreed or strongly agreed that they would be able to differentiate their PE lessons to meet individual children's needs. Sixty-seven percent $(67 \%)$ also agreed or strongly agreed that they felt confident in teaching children with SEN in their lessons. While these findings are positive, indicating that overall student teachers had positive attitudes towards inclusion, and felt prepared and confident in teaching children with 
SEN, less than half of participants (42\%) attributed this preparedness to the training they received at university. It is unclear; therefore, the level to which inclusion training at ITT has prepared or improved the confidence of the participants who participated in this study. Rather it indicates that there are potentially other factors, such as previous employment and training, which may have been more effective in preparing student teachers to teach inclusively. In order to confirm or deny this, further research would have to be undertaken, perhaps including more qualitative elements, such as semi-structured interviews, in order to add richness to the quantitative findings (Robson, 2006).

\section{Conclusion}

This study has examined the extent to which secondary PE student teachers feel prepared and confident, in terms of the training they receive through ITT, to teach children with SEN in inclusive PE lessons. The findings have been varied in their outcomes. Primarily, it has been found that there is a discrepancy in the level of inclusion training received by BA (Hons) student teachers and PGCE student teachers. In particular, it has been found that the BA (Hons) students appear to be in receipt of more formal training compared with the PGCE students. This was attributed to the amount of time available on each course, with the PGCE students having less time and a much prescribed curriculum. Vickerman and Coates (2009) found similar findings, and in particular Vickerman (2007) has found that HE institutions offering one-year PGCE courses often find it difficult to provide extensive inclusion training within such a tightly packed curriculum. As such, it has been recommended that notions of inclusion are embedded into ITT courses, rather than being bolt-on modules. This will not only promote attitude change amongst student teachers (Avramidis et al, 2000), but will allow for a broad and balanced understanding of inclusion to be gained across the curriculum (DePauw and Doll-Tepper, 2000).

In addition, it was found that student teachers are being expected to teach children with a range of different SEN within their in-school placements, although the majority have taught 
children with BESD. Nevertheless, student teachers should be given the opportunity to not only gain practical experience of teaching children with a wide range of SEN - perhaps through special school placements if this is not possible in mainstream schools. They should also be given the theoretical knowledge and understanding of a range of SEN so that they are aware of what might be encountered, how to meet a wide range of pupil needs and how to overcome challenges within lessons. In particular, activity-specific PE training should be made available, and moreover, increased contact with children with SEN through hands-on experience is required.

The sporting tradition (Smith and Green, 2004) and preference for games activities should also be challenged by ensuring student teachers are given the opportunity to experience and teach from a wide range of different activity areas. This could go some way to ensuring they are prepared and confident to teach from a diverse range of activities, rather than just traditional competitive games activities. In addition, cultural preferences need to be challenged, and students encouraged to try out different activities in order to broaden their own experiences, and therefore the experiences of their pupils.

Finally, it was discovered that while the participants generally felt prepared and confident to teach children with SEN, displaying positive attitudes for inclusion; few attributed this to their training at ITT. In response to the research question "Are secondary physical education student teachers sufficiently prepared to teach in inclusive environments?" it is evident that yes, student teachers do feel somewhat prepared and confident to teach in inclusive environments. However it is not clear what contribution their ITT training has made to these feelings. As such, it is recommended that further research, including more qualitative aspects, is undertaken to try and understand why student teachers feel prepared and confident if they perceive their ITT inclusion training as ineffective, as found in this study. 
The findings of this research demonstrate the application of values pertinent to high quality teaching in $\mathrm{HE}$, such as a commitment to scholarship and continued reflection on professional practice, and an understanding of the ways in which students learn and develop (Staff and Educational Development Association (SEDA), 2010). It is necessary through applying these values to research to demonstrate the outcomes research can have on $\mathrm{HE}$ practice, and as such, it is intended that by highlighting the concerns raised within this study, that improvements can be made to the ways in which student teachers are trained which will impact upon their future practice as PE teachers.

In understanding the findings of this study, it is possible to determine the use of such research within HE, and in particular, its application to PE QTS courses. HE institutions should embrace the use of more practical, hands on experience for the student teachers, which focus on the practical application of inclusion skills. Currently, it appears that inclusion education for PE student teachers is too focused upon the theoretical understanding of what SEN is, rather than how to teach children with SEN in mainstream environments. This is not only evidenced by the perceptions of student teachers that much of the SEN training comes in the form of lectures, but in the desire from these student teachers to participate in more formal practical SEN teaching during school placements. Perhaps the assessment of inclusive teaching within school placements could become a method for ensuring student teachers are able to design and deliver lessons which are inclusive. Moreover, providing student teacher with the opportunity to teach in special schools may provide a better perspective of practical ideas to teach children with diverse SEN. These suggestions are not extensive, yet they provide scope for the utilisation of scholarly research within curriculum design and the development and progression of teacher training courses to meet the needs of contemporary education.

\section{References}


Ainscow, M., Farrell, P., Tweddle, D. and Malki, G. (1999) Effective Practice in Inclusion and in Special and Mainstream Schools Working Together, London: DfEE

Allan, J., Brown, S. and Riddell, S. (2005) Permission to Speak: Theorising Special Education in the Classroom, in C. Clark, A. Dyson and A. Millward, Theorising Special Education, Oxon: Routledge

Armstrong, D. (2005) Reinventing 'Inclusion': New Labour and the Cultural Politics of Special Education, Oxford Review of Education, 31(1), 135 - 151

Avramidis, E., Bayliss, P. and Burden, R. (2000) A Survey into Mainstream Teachers' Attitudes towards the Inclusion of Children with Special Educational Needs in the Ordinary School in one Local Education Authority; Educational Psychology, 20(2), 191 - 211

Booth, T., Ainscow, M., Black-Hawkins, K., Vaughan, M. and Shaw, L (2000) Index for Inclusion: Developing Learning and Participation in Schools, Bristol: Centre for Studies on Inclusive Education

British Educational Research Association (BERA) (2004) Revised Ethical Guidelines for Educational Research, Nottingham, BERA

Bryman, A. (2001) Social Research Methods, Oxford: Oxford University Press

Clark, C., Dyson, A., Millward. A. and Robson, S. (1999) Theories of Inclusion, Theories of School: deconstructing and reconstructing the inclusive school, British Educational Research Journal, 25(2), $157-177$

Coates, J. and Vickerman, P. (2008) Let the children have their say: A review of children with special educational needs experiences of Physical Education, Support for Learning, 23(4), $168-175$

Cohen, L., Manion, L. and Morrison, K. (2007) Research Methods in Education (Sixth Edition), Oxon: Routledge

Connors, C. and Stalker, K. (2007) Children's experiences of disability: pointers to a social model of childhood disability, Disability and Society, 22(1), $19-33$

Department for Children, Schools and families (DCSF) (2008) Physical Education and Sport Strategy for Young People, London: HMSO

Department for Education and Skills (DfES) (2001a) Special Educational Needs Code of Practice, HMSO, London

Department for Education and Skills (DfES) (2001b) Special Educational Needs and Disability Act, HMSO, London 
Department for Education and Skills (DfES) (2004) Removing Barriers to Achievement: The Governments Strategy for SEN, Nottingham: DfES Publications

Department for Education and Skills (DfES) (2005) Every Child Matters: Change for Children, London: HMSO

Department for Education and Skills (DfES) (2007) Special Educational Needs In England: January 2007, London: HMSO

DePauw, K. and Doll-Tepper, G. (2000) Toward Progressive Inclusion and Acceptance: Myth or Reality? The Inclusion Debate and Bandwagon Discourse, Adapted Physical Activity Quarterly, 17, 135 - 143

Farrell, P (2000) The impact of research on developments in inclusive education, International journal of Inclusive Education, 4(2), 153 - 162

Golder, G., Norwich, B. and Bayliss, P (2005) Preparing Teachers To Teach Pupils With Special Educational Needs In More Inclusive Schools: Evaluating A PGCE Development, British Journal of Special Education, 32(2), $92-99$

Hodge, S., Ammah, J., Casebolt, K., LaMaster, K. and O'Sullivan, M. (2004) High school general physical education teachers' behaviours and beliefs associated with inclusion, Sport, Education and Society, 9(3), 395-420.

Hodkinson, A. and Vickerman, P (2008) Key Issues in Special Educational Needs, London: Sage

Jones, P. (2005) Teacher's Views of their Pupils with Profound and Multiple Learning Difficulties, European Journal of Special Needs Education, 20:4, 375 - 385

Low, C. (2007) A Defence of Moderate Inclusion, in Cigman, R. (Ed), Included or Excluded? The Challenge of the Mainstream for Some SEN Children, Oxon: Routledge

Morley, D., Bailey, R., Tan, J. and Cooke, B. (2005) Inclusive physical education: teachers' views of teaching children with special educational needs and disabilities in physical education, European Physical Education Review, 11(1), 84-107

Norwich, B (2002) Education, Inclusion and Individual Differences: Recognising and Resolving Dilemmas, British Journal of Education Studies, 50(4), 482-502

Penney, D. (2002) Equality, equity and inclusion in physical education and school sport, in: Laker, A. (Eds), The Sociology of sport and Physical Education, London: Routledge Falmer

Quality Assurance Agency for Higher Education (2007) Education Studies, available at http://www.qaa.ac.uk/academicinfrastructure/benchmark/honours/Education07.pdf, last accessed 01/12/2010 
Qualifications and Curriculum Authority (2009) National Curriculum, available at http://curriculum.qcda.gov.uk/index.aspx, last accessed 17/12/2009

Robertson, C. (1999) Improving Training: Initial Teacher Education and Inclusive Schooling, Support for Learning, 14(4), 169 - 173

Robson, C. (2006) Real World Research: A Resource for Social Scientists and Practitioner Researchers (Second Edition), Oxford: Blackwell Publishing

SEDA (2010) Core Mission and Vales, available from

http://www.seda.ac.uk/index.php?p=2_1, last accessed 07/06/2010

Smith, A. (2004) The Inclusion of Pupils with Special education Needs in Secondary School Physical Education, Physical Education and Sport Pedagogy, 9(1) 37 - 54

Smith, A. and Green, K. (2004) Including pupils with special educational needs in secondary school physical education: a sociological analysis of teachers' views, British Journal of Sociology of Education, 25(5), 593-608.

Smith, A. and Thomas, N. (2006) Including pupils with Special Educational Needs and Disabilities in National Curriculum Physical Education: a brief review; European Journal of Special Needs Education, Volume 21(1), $69-83$

Training and Development Agency for Schools (2006) Qualifying to Teach: Professional standards for qualified teacher status and requirements for initial teacher training, London: TDA

Vickerman, P. (2002) Perspectives on the Training of Physical Education Teachers for the Inclusion of Children with Special Educational Needs: Is There an Official Line View? Bulletin of Physical Education, 38(2), 79 - 98

Vickerman, P. (2007) Training Physical Education Teachers to Include Children with Special Educational Needs: Perspectives from Physical Education Teacher Training Providers, European Physical Education Review, 18(3), 285 - 402

Vickerman, P. and Coates, J. (2009) Trainee and Recently Qualified Physical Education Teachers Perspectives on Including Children with Special Educational Needs, Physical Education and Sport Pedagogy, 14:2, $137-153$

Warnock, M. (1978) Special Educational Needs: Report of the Committee of Enquiry into the Education of Handicapped Children, London: HMSO 
Table One: Statistical results generated from the questionnaire data.

\begin{tabular}{|c|c|c|c|c|c|}
\hline \multirow{2}{*}{\begin{tabular}{|c|}
$\begin{array}{c}\text { Questionnaire } \\
\text { Section }\end{array}$ \\
Training
\end{tabular}} & \multirow[t]{2}{*}{ Question } & \multirow[t]{2}{*}{ Response } & \multicolumn{2}{|c|}{ Degree Course } & \multirow[b]{2}{*}{$\begin{array}{c}\text { Total } \\
\text { for both } \\
\text { degree } \\
\text { courses }\end{array}$} \\
\hline & & & $\begin{array}{c}\text { BA } \\
\text { (Hons) } \\
\text { PE, } \\
\text { Sport } \\
\text { and } \\
\text { Dance } \\
\text { (QTS) } \\
(\%)\end{array}$ & $\begin{array}{l}\text { PGCE } \\
\text { PE (\%) }\end{array}$ & \\
\hline & \multirow[t]{3}{*}{ Have you had any SEN inclusion training during your Initial Teacher Training? } & Yes & 98 & 78 & 87 \\
\hline & & No & 2 & 16 & 9 \\
\hline & & Not Sure & 0 & 6.9 & 4 \\
\hline & \multirow[t]{3}{*}{ What was the nature of this training? } & General SEN & 29 & 42 & 35 \\
\hline & & $\begin{array}{l}\text { PE Specific } \\
\text { SEN }\end{array}$ & 35 & 21 & 28 \\
\hline & & Both & 35 & 38 & 37 \\
\hline & How was the training delivered? & $\begin{array}{l}\text { Mandatory } \\
\text { taught module }\end{array}$ & 75 & 52 & 64 \\
\hline
\end{tabular}




\begin{tabular}{|c|c|c|c|c|}
\hline & $\begin{array}{l}\text { Optional taught } \\
\text { module }\end{array}$ & 6 & 4 & 5 \\
\hline & $\begin{array}{l}\text { Formal in- } \\
\text { school training }\end{array}$ & 33 & 42 & 38 \\
\hline & $\begin{array}{l}\text { Informal in- } \\
\text { school } \\
\text { experience }\end{array}$ & 29 & 15 & 22 \\
\hline \multirow{5}{*}{ How effective was the training? } & Very effective & 0 & 0 & 0 \\
\hline & Effective & 6 & 2 & 4 \\
\hline & Neutral & 10 & 15 & 13 \\
\hline & Ineffective & 63 & 67 & 65 \\
\hline & Very Ineffective & 21 & 17 & 19 \\
\hline \multirow[t]{3}{*}{$\begin{array}{l}\text { Do you feel the training you received increased your confidence in supporting } \\
\text { children with SEN in PE? }\end{array}$} & Yes & 67 & 71 & 10 \\
\hline & No & 17 & 4 & 69 \\
\hline & Not Sure & 17 & 25 & 21 \\
\hline
\end{tabular}




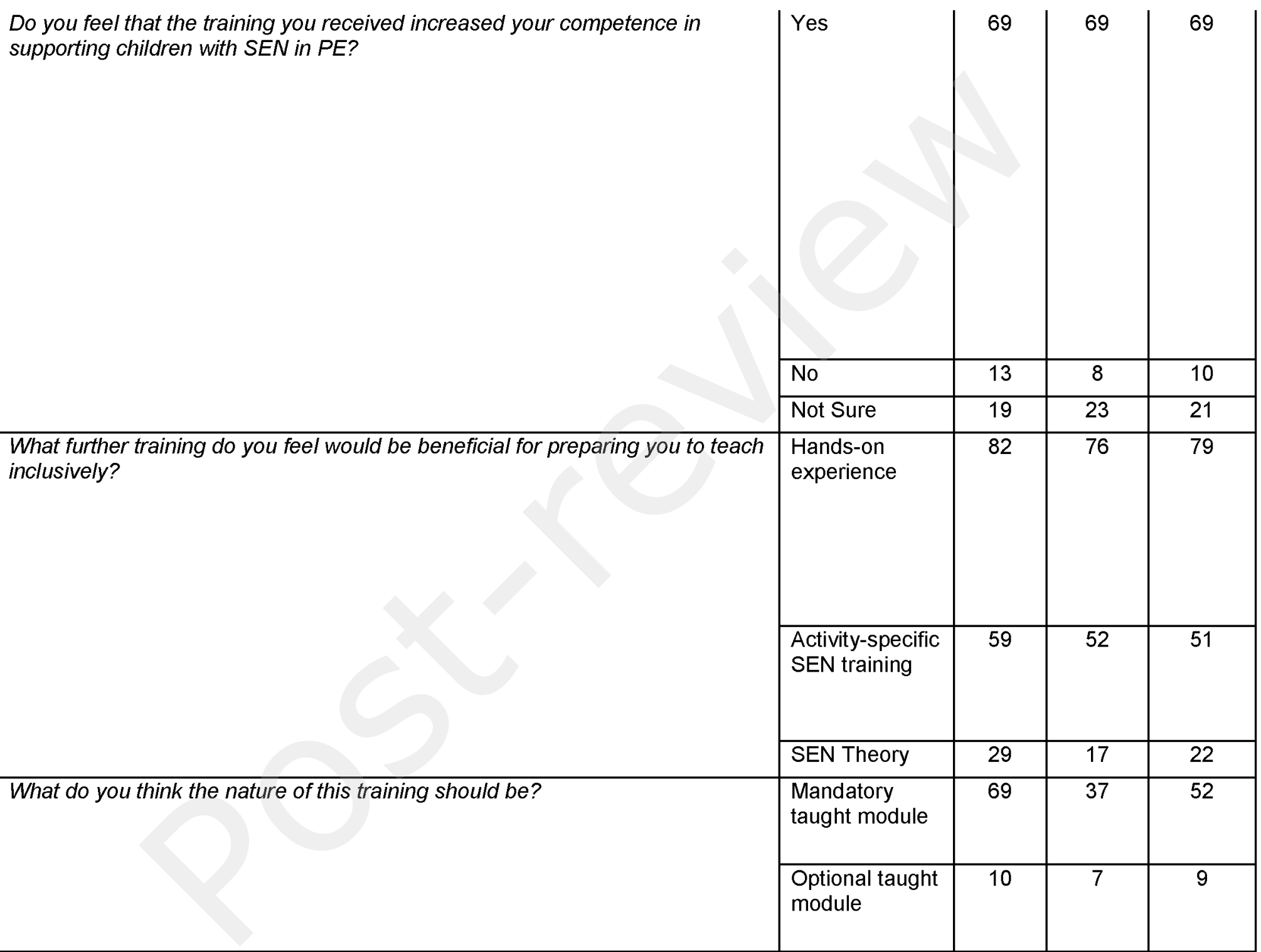




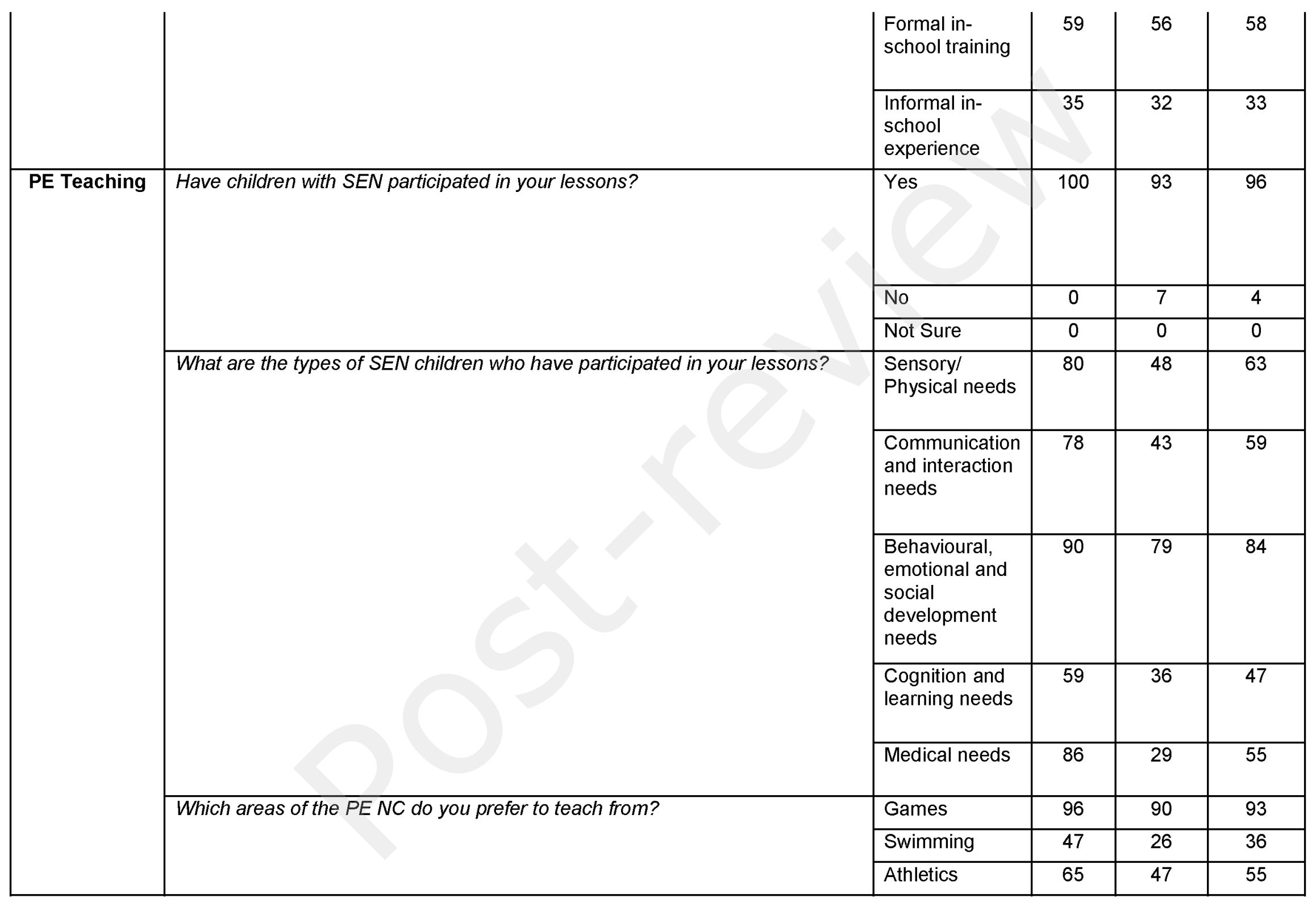




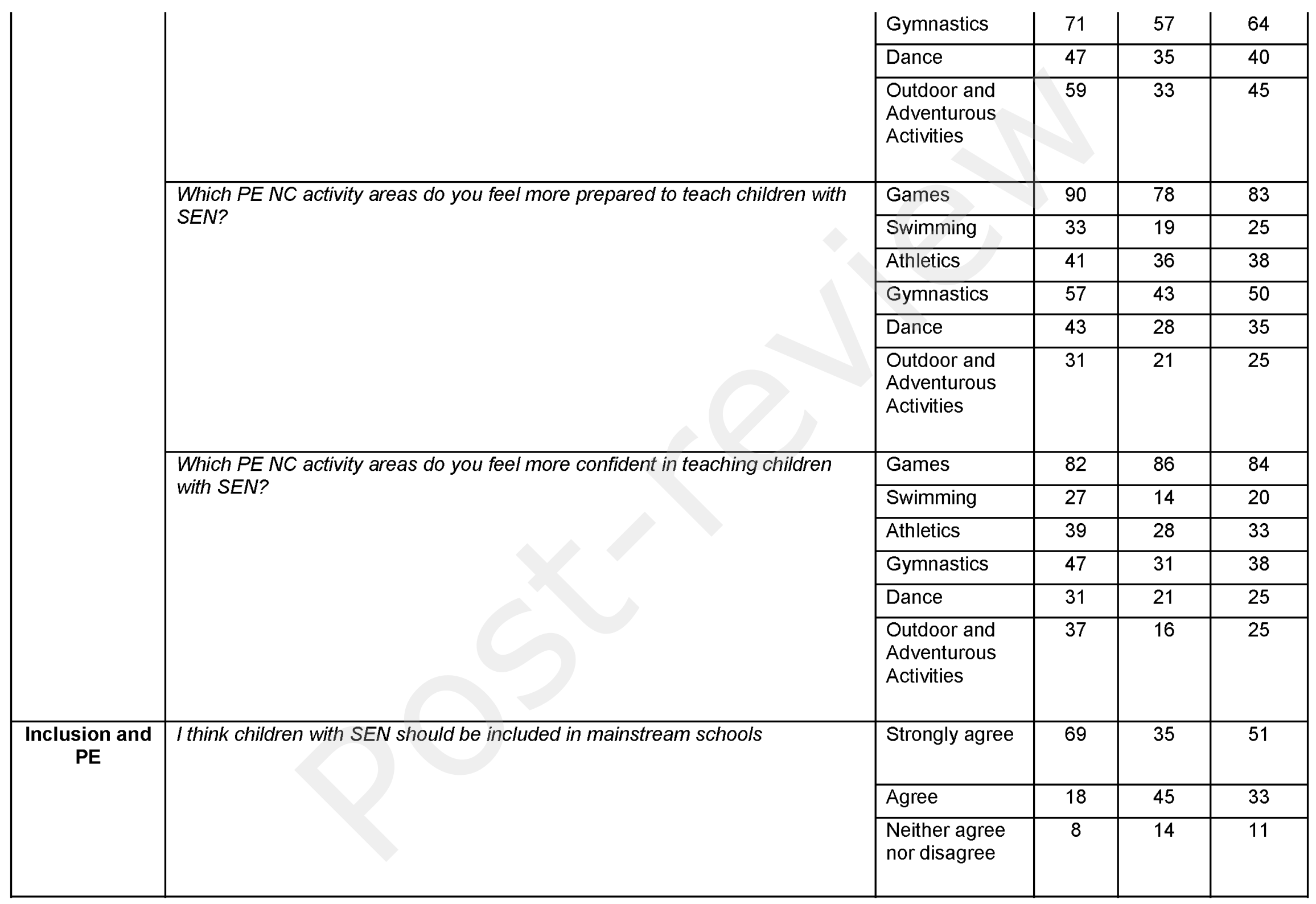




\begin{tabular}{|c|c|c|c|c|}
\hline & Disagree & 2 & 0 & 1 \\
\hline & \begin{tabular}{|l} 
Strongly \\
disagree
\end{tabular} & 2 & 7 & 5 \\
\hline \multirow[t]{5}{*}{ I understand what SEN means } & Strongly agree & 74 & 35 & 52 \\
\hline & Agree & 20 & 59 & 41 \\
\hline & $\begin{array}{l}\text { Neither agree } \\
\text { nor disagree }\end{array}$ & 2 & 0 & 1 \\
\hline & Disagree & 2 & 0 & 1 \\
\hline & $\begin{array}{l}\begin{array}{l}\text { Strongly } \\
\text { disagree }\end{array} \\
\end{array}$ & 2 & 7 & 5 \\
\hline \multirow[t]{5}{*}{ I understand what inclusion is } & Strongly agree & 74 & 5 & 61 \\
\hline & Agree & 22 & 2 & 32 \\
\hline & $\begin{array}{l}\text { Neither agree } \\
\text { nor disagree }\end{array}$ & 0 & 3 & 2 \\
\hline & Disagree & 0 & 40 & 1 \\
\hline & \begin{tabular}{|l|} 
Strongly \\
disagree
\end{tabular} & 4 & 50 & 5 \\
\hline \multirow[t]{5}{*}{ I am worried about teaching children with SEN } & Strongly agree & 2 & 2 & 2 \\
\hline & Agree & 25 & 14 & 19 \\
\hline & $\begin{array}{l}\text { Neither agree } \\
\text { nor disagree }\end{array}$ & 16 & 40 & 29 \\
\hline & Disagree & 16 & 24 & 21 \\
\hline & $\begin{array}{l}\text { Strongly } \\
\text { disagree }\end{array}$ & 41 & 21 & 30 \\
\hline
\end{tabular}




\begin{tabular}{|c|c|c|c|c|}
\hline \multirow{5}{*}{$\begin{array}{l}\text { I am able to adapt/ differentiate my lessons to meet the needs of children with } \\
\text { SEN }\end{array}$} & Strongly agree & 39 & 14 & 25 \\
\hline & Agree & 49 & 50 & 50 \\
\hline & $\begin{array}{l}\text { Neither agree } \\
\text { nor disagree }\end{array}$ & 8 & 19 & 14 \\
\hline & Disagree & 4 & 17 & 11 \\
\hline & $\begin{array}{l}\text { Strongly } \\
\text { disagree }\end{array}$ & 0 & 0 & 0 \\
\hline \multirow[t]{5}{*}{ I feel university has prepared me to teach children with SEN } & Strongly agree & 12 & 3 & 6 \\
\hline & Agree & 43 & 12 & 36 \\
\hline & $\begin{array}{l}\text { Neither agree } \\
\text { nor disagree }\end{array}$ & 31 & 53 & 43 \\
\hline & Disagree & 10 & 31 & 11 \\
\hline & $\begin{array}{l}\text { Strongly } \\
\text { disagree }\end{array}$ & 4 & 0 & 4 \\
\hline \multirow[t]{5}{*}{ I feel confident when I teach children with SEN } & Strongly agree & 31 & 7 & 18 \\
\hline & Agree & 45 & 53 & 50 \\
\hline & $\begin{array}{l}\text { Neither agree } \\
\text { nor disagree }\end{array}$ & 18 & 31 & 25 \\
\hline & Disagree & 4 & 9 & 7 \\
\hline & $\begin{array}{l}\text { Strongly } \\
\text { disagree }\end{array}$ & 2 & 0 & 1 \\
\hline
\end{tabular}


1

33 